\title{
Finite Element Analysis on a Square Canister Piezoelectric Energy Harvester in Asphalt Pavement
}

\author{
Hongbing Wang, Chunhua Sun \\ Department of Mechanical \& Electrical Engineering, Suzhou Vocational University, Suzhou, China \\ Email:whb@jssvc.edu.cn
}

Received 2 April 2016; accepted 28 May 2016; published 31 May 2016

Copyright (C) 2016 by authors and Scientific Research Publishing Inc.

This work is licensed under the Creative Commons Attribution International License (CC BY).

http://creativecommons.org/licenses/by/4.0/

(c) ()) Open Access

\begin{abstract}
A novel square canister piezoelectric energy harvester was proposed for harvesting energy from asphalt pavement. The square of the harvester was of great advantage to compose the harvester array for harvesting energy from the asphalt pavement in a large scale. The open circuit voltage of the harvester was obtained by the piezoelectric constant $d_{33}$ of the piezoelectric ceramic. The harvester is different from the cymbal harvester which works by the piezoelectric constant $d_{31}$. The finite element model of the single harvester was constructed. The open circuit voltage increased with increase of the outer load. The finite element model of the single harvester buried in the asphalt pavement was built. The open circuit voltage, the deformation difference percent and the stress of the ceramic of the harvester were obtained with different buried depth. The open circuit voltage decreased when the buried depth was increased. The proper buried depth of the harvester should be selected as $30-50 \mathrm{~mm}$. The effects of structure parameters on the open circuit voltage were gotten. The output voltage about $64.442 \mathrm{~V}$ could be obtained from a single harvester buried under $40 \mathrm{~mm}$ pavement at the vehicle load of $0.7 \mathrm{MPa} .0 .047 \mathrm{~mJ}$ electric energy could be gotten in the harvester. The output power was about $0.705 \mathrm{~mW}$ at $15 \mathrm{~Hz}$ vehicle load frequency.
\end{abstract}

\section{Keywords}

Asphalt Pavement Vibration Energy, Square Canister, Piezoelectric Energy Harvester, Finite Element Method

\section{Introduction}

It was a grand challenge to find the reproducible green resources for human civilization progress with the short-

How to cite this paper: Wang, H.B. and Sun, C.H. (2016) Finite Element Analysis on a Square Canister Piezoelectric Energy Harvester in Asphalt Pavement. World Journal of Engineering and Technology, 4, 361-373.

http://dx.doi.org/10.4236/wjet.2016.42035 
age of the traditional resources such as petroleum, coal and natural gas. Energy harvesting from wasted power which existed in various forms such as industrial machines, structures and environment sources had been a topic of discussion in the last decades. Energy harvesting technology could change vibration energy into electrical energy by recycling wasted vibration energy [1]. Methods of energy conversion of vibration to electrical energy were piezoelectric, electromagnetic and electrostatic [2]-[4]. It had been proved that piezoelectric transducers were more suitable for vibration to electrical energy converters. In addition to the advantage of being smaller and lighter the piezoelectric had three times higher energy density as compared to their counterparts electrostatic and electromagnetics [5]. Asphalt pavement was widely used in many countries. In china the mileages of the asphalt pavement were about 641,900 km at the end of 2012 [6]. When many vehicles moved on the asphalt pavement, the loads of the vehicles could cause vibration in the asphalt pavement. When piezoelectric transducers were buried in the pavement, the vibration energy could be converted into electric energy. In the last decades, many researches in the world started to study the technology of piezoelectric energy harvesting from the asphalt pavement. In 2008, a piezoelectric energy harvesting system named as IPEG ${ }^{\mathrm{TM}}$ was designed and used by Israelis researches [7]. The system could produce up to $0.4 \mathrm{MW} / \mathrm{KM}$ electric energies in the bidirectional roadways when the traffics were about 600 vehicles in an hour. Literature [8] studied piezoelectric energy conversion efficiency. Literature [9] invented a shoe which could produce electric energy. The shoe could produce about 80 $\mathrm{mW}$ energy. Literature [10] invented an intellectual floor which could convert piezoelectric energy into electric energy. Literature [11] studied a cymbal transducer buried in the asphalt pavement. The transducer could harvest vibration energy in the asphalt pavement. The cymbal transducer worked by using the tangential piezoelectric constant coefficient $d_{31}$. The electromechanical coupling coefficient of the cymbal transducer was not high. Literature [12] designed a drum transducer which worked by using the longitudinal piezoelectric constant parameter $d_{33}$. The electromechanical coupling coefficient of the drum transducer was higher than that of the cymbal transducer.

For harvesting vibration energy in the asphalt pavement effectively in a large scale, a square canister piezoelectric energy harvester was proposed. The harvester worked by using the piezoelectric constant $d_{33}$. Because of narrow space in the asphalt pavement, the harvester should be arrayed in rectangle. So in contrast to the circle harvester, the square harvester could economize space in the asphalt pavement and advance total electric power.

The paper firstly studied the vibration characteristic of the harvester by FEM. The effect of the outer load on the open circuit voltage of the harvester was analyzed. Then the harvesting capability of the harvester which was buried in the asphalt pavement was analyzed and the effect of different burying depth in the asphalt pavement was analyzed. Lastly the effect of all structure parameters on the open circuit voltage was studied.

\section{Structure and Principle of the Harvester}

The structure of the harvester was shown in Figure 1. The harvester was composed of a square steel ring, two square steel sheets and two piezoelectric ceramics. All parts were clung each other by using glue. The dimensions of the harvester were shown in Figure 1. The material of the piezoelectric ceramic was PZT-8. The ceramic was polarized along the thickness direction and the polarization direction was shown in Figure 1. When the outer load was applied on the plate of the ceramic the internal electrical charge was generated. Because the harvester was buried in the asphalt pavement stainless steel was selected as the material of the ring and sheet to avoid rust. The harvester was arranged in rectangle shape shown in Figure 2. The rectangle arrangement could economize the space of the asphalt pavement and advance total generation energy.

The mode of harvesting vibration energy from the asphalt pavement using piezoelectric harvester was shown in Figure 3.

When moving vehicles passed on the asphalt pavement, the loads of vehicles could cause strain stored in the asphalt pavement as strain energy. The strain energy would dissipate through vibration as waste thermal energy. For utilizing the waste energy the asphalt pavements with piezoelectric harvester were constructed to transform the waste energy into useful electric energy.

\section{Piezoelectric Effect of the Harvester}

The piezoelectric effect was understood as the linear electromechanical interaction between the mechanical and the electrical state in piezoelectric ceramic. The piezoelectric effect was a reversible process exhibiting the direct piezoelectric effect (the internal generation of electrical charge resulting from an applied mechanical force) 


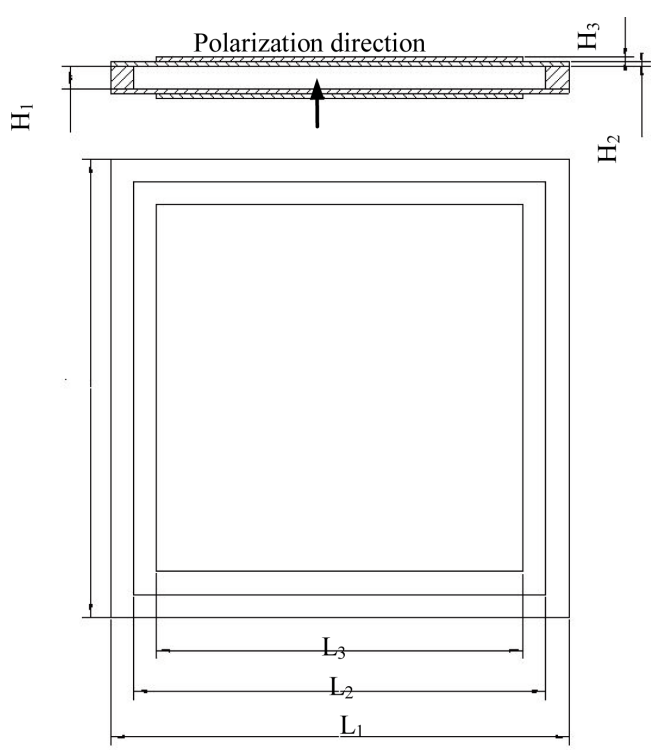

Figure 1. Structure of the harvester.

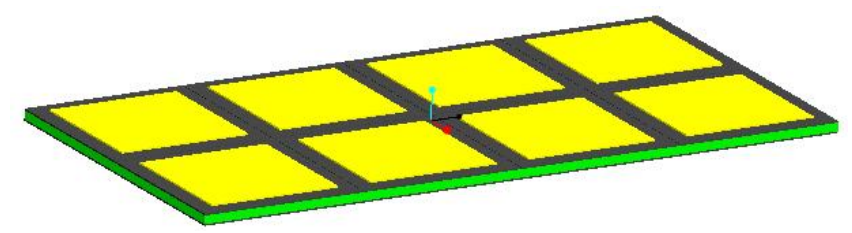

Figure 2. The harvester arrangement buried under the asphalt pavement.

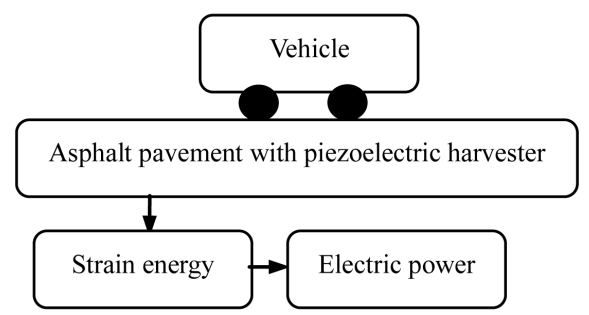

Figure 3. The harvester arrangement buried under the asphalt pavement.

and the reverse piezoelectric effect (the internal generation of a mechanical strain resulting from an applied electrical field). The piezoelectric equation of the harvester which buried in the asphalt pavement could be described as Equations (1) and (2).

$$
\begin{gathered}
S_{i}=s_{i j}^{E} T_{j}+d_{n i} E_{n} \\
D_{m}=d_{m} T_{j}+\varepsilon_{m n}^{T} E_{n}
\end{gathered}
$$

where $i, j=1,2,3,4,5,6 ; m, n=1,2,3, D$ was the electric displacement; $E$ was electric field intensity; $d$ was the piezoelectric constant matrix; $S$ was the strain tensor; $T$ was the stress tensor; $\varepsilon^{T}$ was the dielectric constant tensor tested at constant stress condition; $s^{E}$ was the compliance tensor tested at constant electric field intensity condition.

When the harvester was buried in the asphalt pavement, the direct piezoelectric effect could be used to transform the vibration energy into the electric energy. In the condition the outer electric field intensity $E=0$. When the vertical loads of vehicles were applied on the asphalt pavement, the direction of the loads was accord with 
the polarization direction along thickness of the piezoelectric ceramic. The Equation (2) could be described as the Equation (3).

$$
D_{3}=\sum_{i=1}^{6} d_{3 i} T_{i}
$$

From the relation of $D$ and $E$ the Equation (4) could be concluded.

$$
E_{3}=D_{3} / \varepsilon_{r}^{T} \varepsilon_{0}=\sum_{i=1}^{6} d_{3 i} T_{i} / \varepsilon_{r}^{T} \varepsilon_{0}
$$

where, $\varepsilon_{0}$ was the permittivity of vacuum; $\varepsilon_{r}^{T}$ was the relative permittivity. So the open circuit voltage $V_{3}$ at the thickness direction of the ceramic could be concluded as the Equation (5).

$$
V_{3}=\int E_{3} \mathrm{~d} m=\sum_{i=1}^{6} \int \frac{d_{3 i} T_{i}}{\varepsilon_{r}^{T} \varepsilon_{0}} \mathrm{~d} m
$$

where $m$ was the thickness of the piezoelectric ceramic. In Figure 1 we could conclude that $m=H_{3}$.

The electric energy stored in the harvester could be concluded as the Equation (6).

$$
U=\frac{1}{2} q_{3} E_{3} A m=\frac{1}{2} V^{2} \frac{\varepsilon_{r}^{T} \varepsilon_{0} A}{m}
$$

where $A$ was the area of the piezoelectric ceramic. In Figure 1 we could conclude that $A=L_{3} \times L_{3}$.

\section{Finite Element Analysis of the Single Harvester}

Finite element software ANSYS was used to analyze the open circuit voltage of the harvester with different outer load. The initial structure parameters of the harvester were showed in Table 1. The materials of the steel ring and sheet were stainless. The material properties of stainless steel were Elastic module $209 \mathrm{GPa}$, Poisson ratio 0.267 and Density $7860 \mathrm{~kg} / \mathrm{m}^{3}$. The material of the piezoelectric ceramic was PZT-8 whose properties were shown in Table 2.

The finite element model of the harvester was shown in Figure 4. In the model the influence of the adjoin part was ignored and the connection of the ceramic and the steel sheet was ideal. The displacement and stress were continual in the adjoin part.

In Figure 4 the distribution load was applied on the surface of the two ceramics. As result the open circuit voltage was generated on the surface of the two ceramics. When the outer load was $2000 \mathrm{~Pa}$, the open circuit voltage was shown in Figure 5. The open circuit voltage on the surface of the two ceramics was equal and the open circuit voltage was about $2.076 \mathrm{~V}$.

The relation of the open circuit voltage and the outer load was shown in Figure 6. The open circuit voltage increased with the outer load increasing.

When the harvester was buried in the asphalt pavement the harvester was deformed with the asphalt pavement under the loads of vehicles. The boundary condition of the harvester was different from the free state of the single harvester. So the harvester and the asphalt pavement should be analyzed as a whole. In the paper finite element method was used to analyze the harvester buried in the asphalt pavement. When the load of a single vehicle was applied on the surface of the asphalt pavement static analysis was used to analyze the deformation state of the harvester and the asphalt pavement and the open circuit voltage. With the load of a single vehicle the effect of the structure parameters of the harvester on the open circuit voltage was analyzed.

\section{Finite Element Analysis of the Harvester Buried in the Asphalt Pavement}

\subsection{The Effect of the Buried Depth of the Harvester}

The finite element model of the harvester buried in the asphalt pavement was shown in Figure 7. Refer to literature [11], the load of a large car was $0.7 \mathrm{MPa}$. The diameter of the load area was $213 \mathrm{~mm}$. At the place of the asphalt pavement from the load area about $500 \mathrm{~mm}$, the load had no influence on the asphalt pavement. So the diameter of the asphalt pavement was $1000 \mathrm{~mm}$. The two ends of the asphalt pavement were fixed. From criterion the thickness of the asphalt pavement was $150 \mathrm{~mm}$, so the height of the asphalt pavement was $150 \mathrm{~mm}$. 
Table 1. Initial structure parameters of the harvester.

\begin{tabular}{|c|c|c|c|c|}
\hline & \multicolumn{2}{|c|}{ The steel ring } & The ceramic & The steel sheet \\
\hline $\begin{array}{l}\text { Length } \times \text { Width } \\
(\mathrm{mm})\end{array}$ & $\begin{array}{c}\text { Outer dimension } \\
20 \\
\left(L_{1} \times L_{1}\right)\end{array}$ & $\begin{array}{c}\text { Inner dimension } \\
18 \\
\left(L_{2} \times L_{2}\right)\end{array}$ & $\begin{array}{c}16 \\
\left(L_{3} \times L_{3}\right)\end{array}$ & \\
\hline Thickness (mm) & \multicolumn{2}{|c|}{$0.2\left(H_{1}\right)$} & $0.2\left(H_{3}\right)$ & $2\left(H_{2}\right)$ \\
\hline
\end{tabular}

Table 2. Material properties of PZT-8.

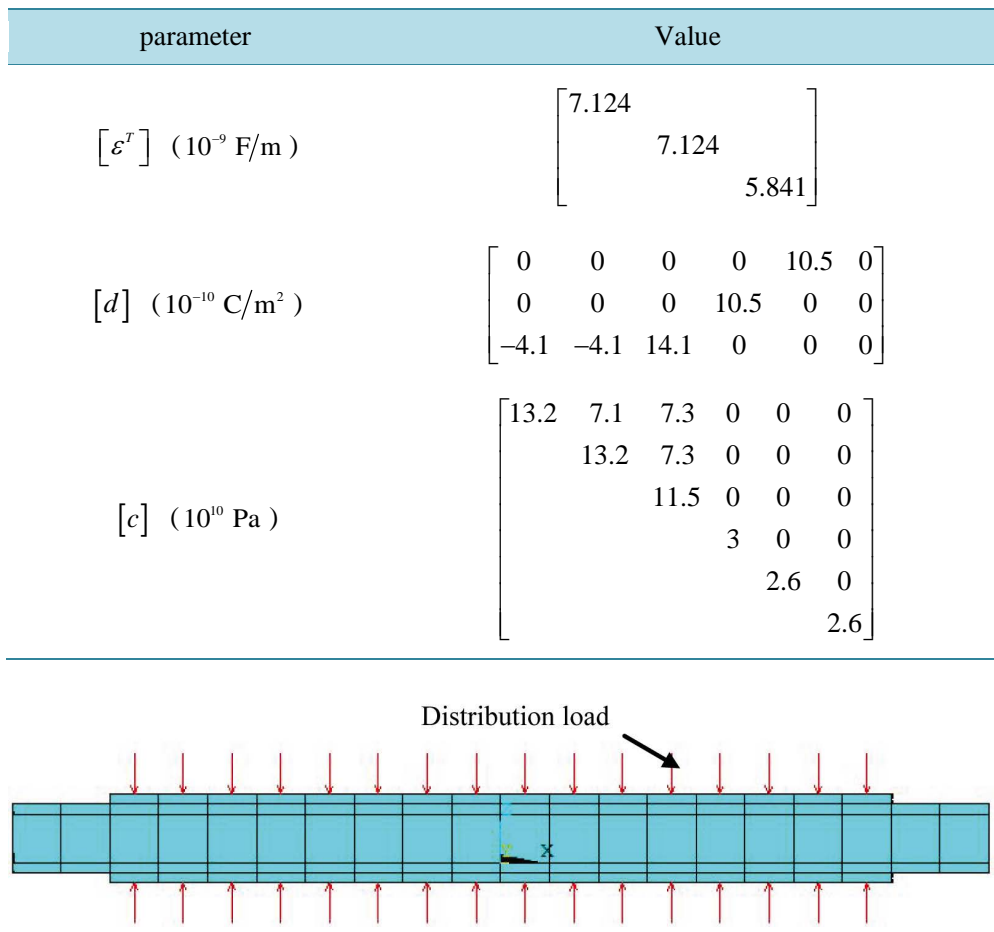

Figure 4. Finite element model of the harvester.
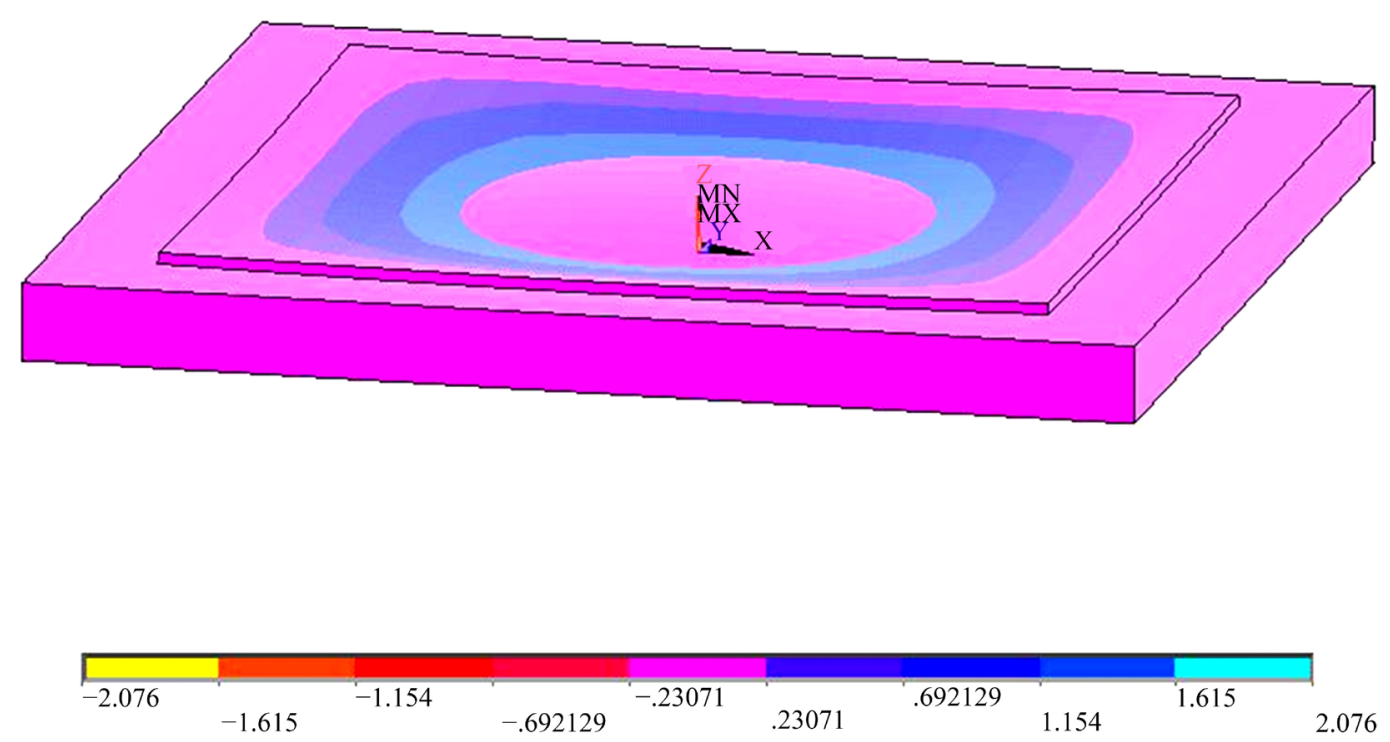

Figure 5. The open circuit voltage of the harvester. 


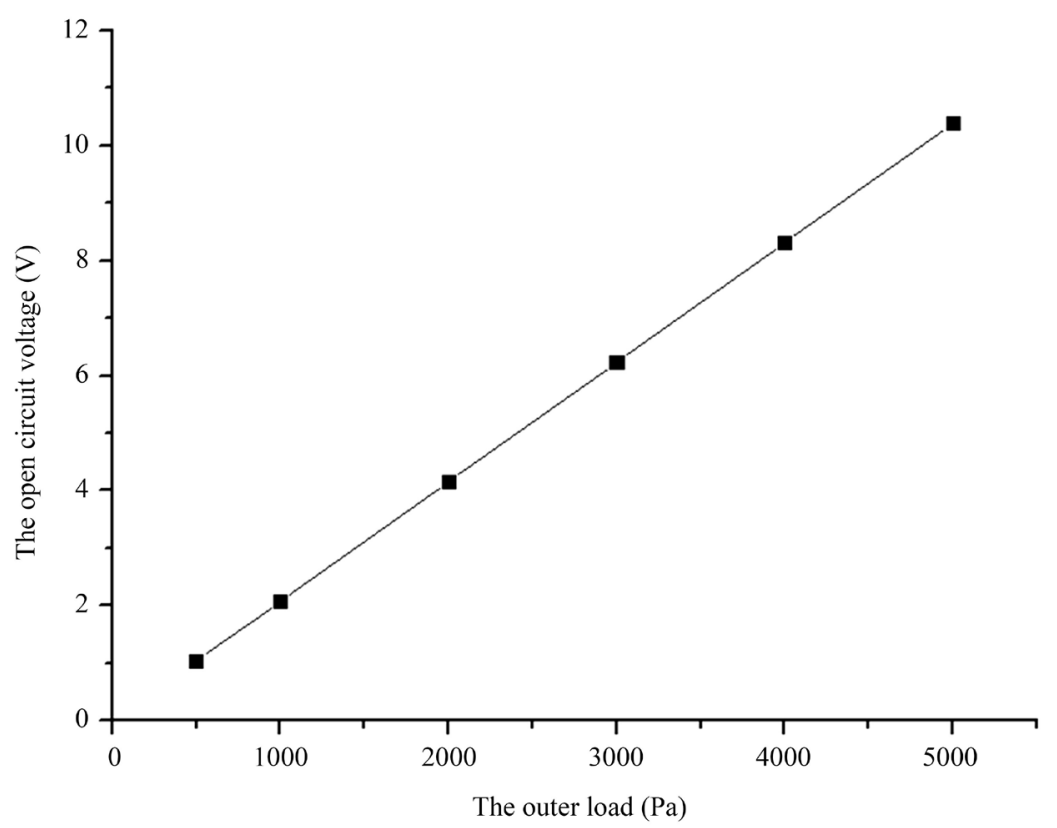

Figure 6. Effect of different outer load on the open circuit voltage.

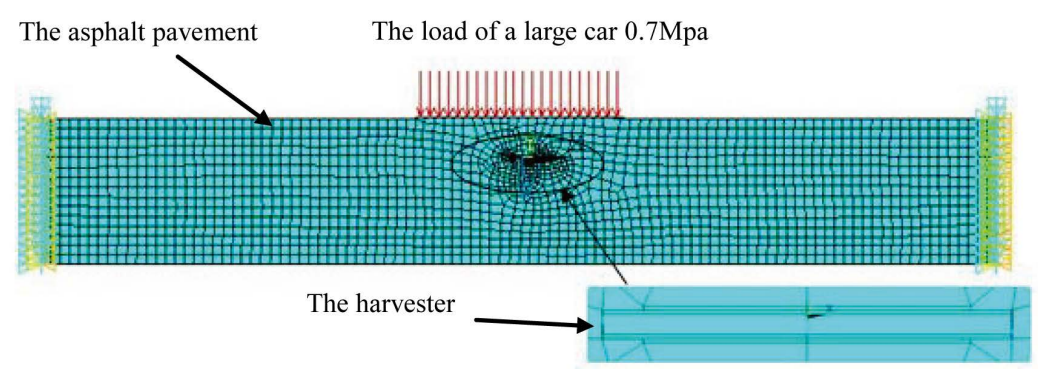

Figure 7. Finite element model of the harvester and the asphalt pavement.

When the harvester was buried in the asphalt pavement, we should not only pay attention to the electric energy generation capacity, but also harmony characteristic with the asphalt pavement. The harmony characteristic was described that the deformation of the asphalt pavement with the harvester was accord with the asphalt pavement without the harvester. Refer to Literature [11], Equation (7) was used to identify the harmony characteristic.

$$
p=\frac{\varepsilon_{o}-\varepsilon_{w}}{\varepsilon_{o}} \times 100 \%
$$

where $p$ was the deformation difference percent; $\varepsilon_{o}$ was the deformation without the harvester; $\varepsilon_{w}$ was the deformation with the harvester.

Finite element method was used to analyze the model of the harvester shown in Figure 7. The deformation of the asphalt pavement was shown in Figure 8. The deformation was about $0.638 \mathrm{~mm}$. When the buried depth of the harvester was $10 \mathrm{~mm}$, the deformation of the asphalt pavement was about $0.641 \mathrm{~mm}$ shown in Figure 9 . The open circuit voltage of the harvester was about $138.496 \mathrm{~V}$ shown in Figure 10. The maximal stress of the ceramic was about 68.4 Mpa shown in Figure 11.

The open circuit voltage of the harvester with different buried depth was shown in Figure 12. In Figure 12 the open circuit voltage decreased with the buried depth increasing. The open circuit voltage with the buried depth $40 \mathrm{~mm}$ was about $64.442 \mathrm{~V}$.

According to the Equation (7), when the buried depth was $40 \mathrm{~mm}$, the deformation difference percent $p$ was about $-0.313 \%$. The deformation difference percent $p$ with different buried depth was shown in Figure 13. 


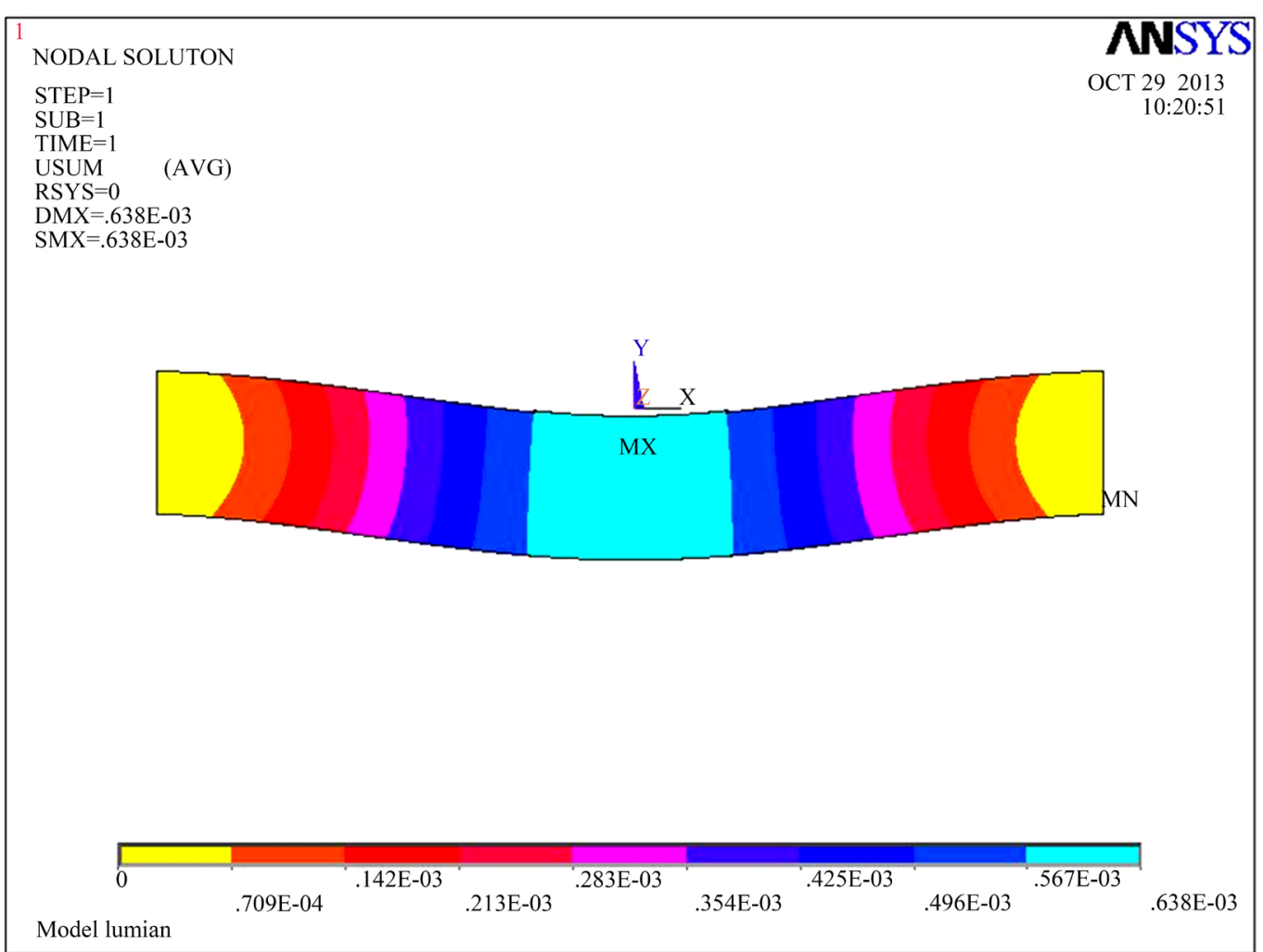

Figure 8. The deformation of the pavement without the harvester.

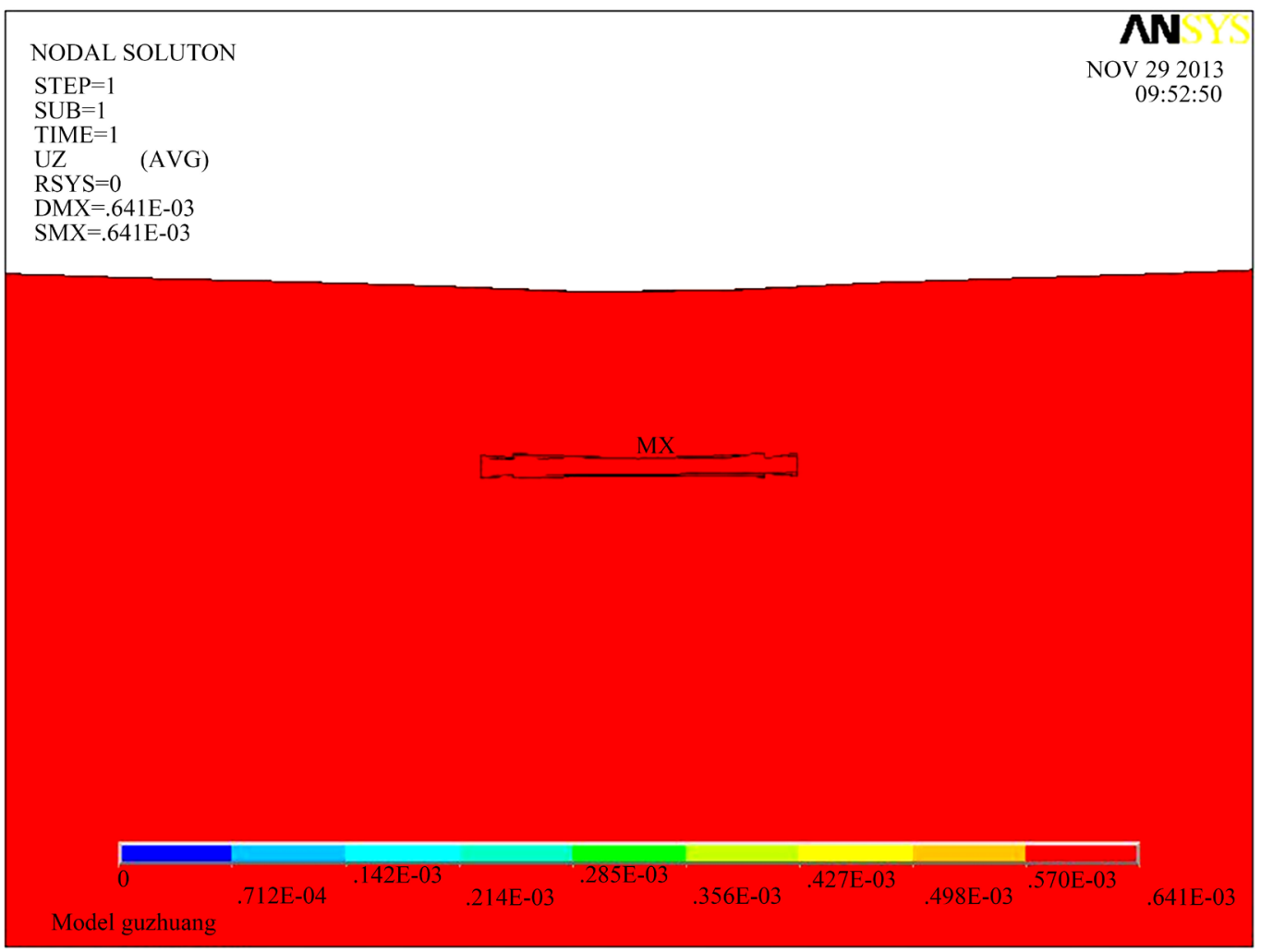

Figure 9. The deformation of the pavement with the harvester. 


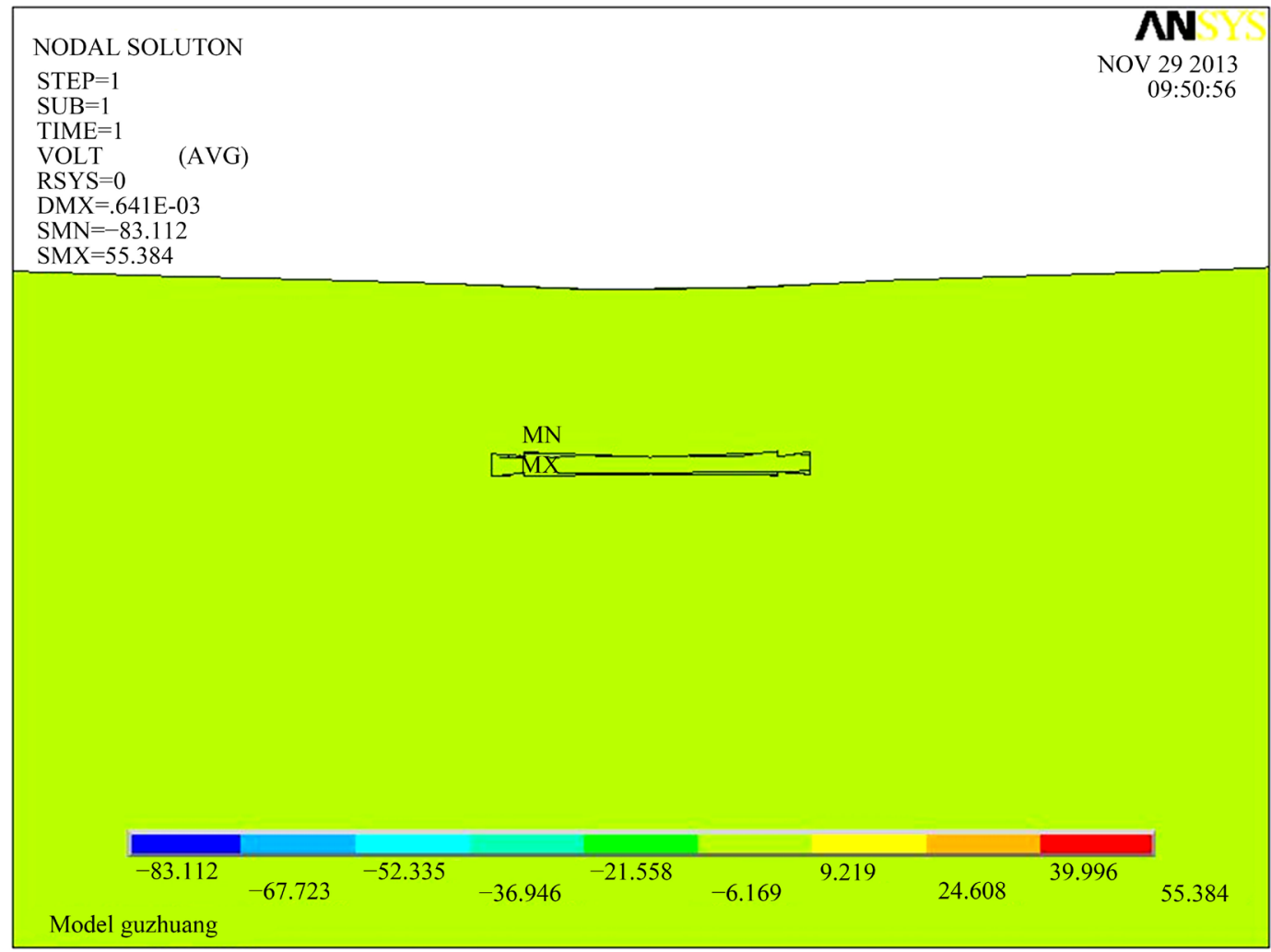

Figure 10. The open circuit voltage of the harvester.

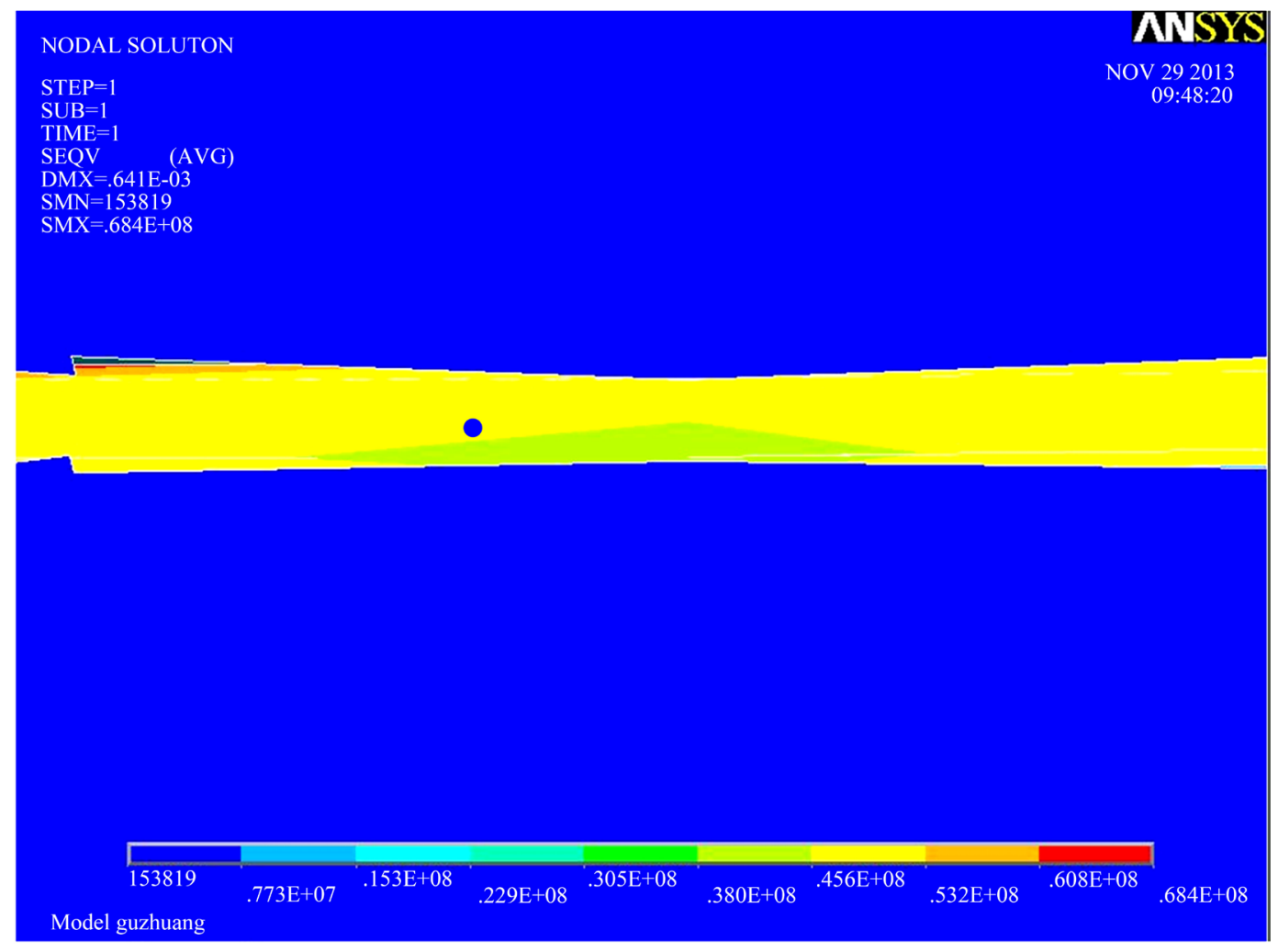

Figure 11. The stress of the harvester and the asphalt pavement. 


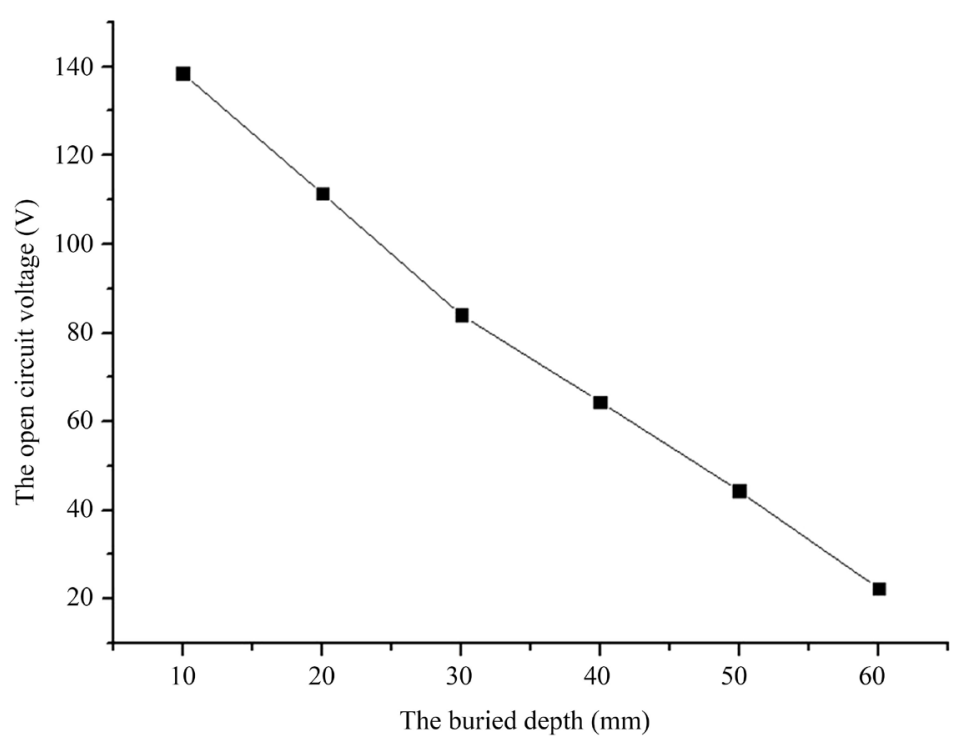

Figure 12. The open circuit voltage with different buried depth.

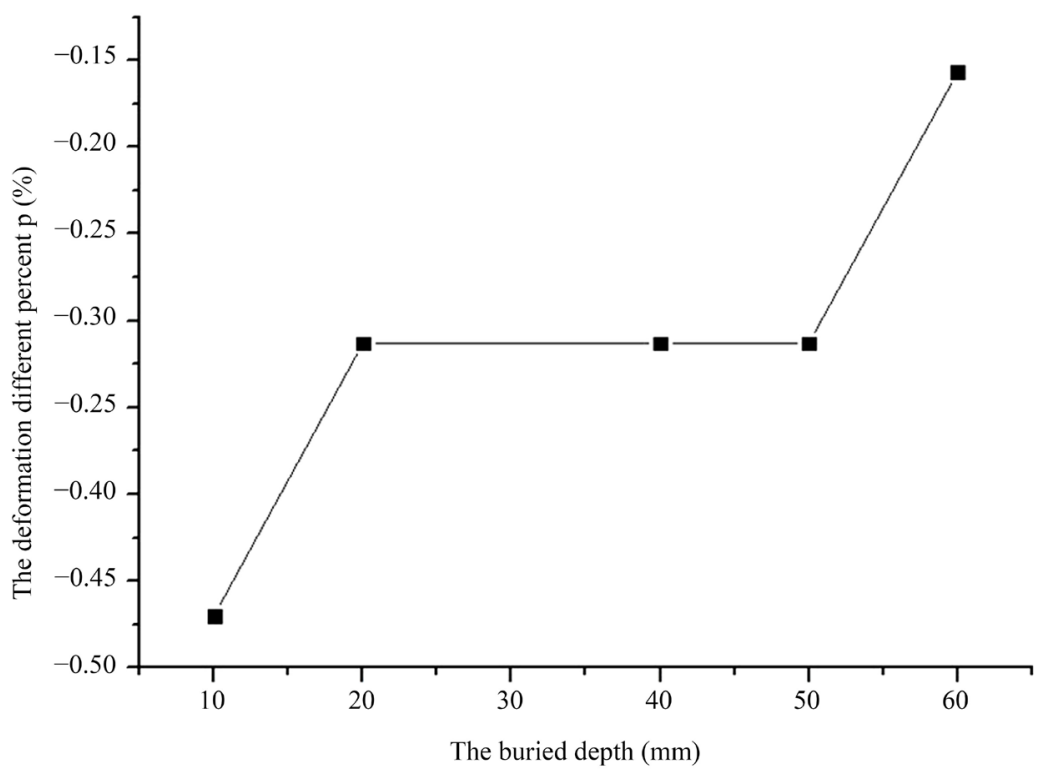

Figure 13. The parameter $p$ with different buried depth.

From Figure 13 we could find that $p$ decreased with the buried depth increasing. Among the buried depth 20 $50 \mathrm{~mm}$ the parameter $p$ kept invariable. When the harvester was closer to the surface of the asphalt pavement the influence on the asphalt pavement was more greatly.

The maximal stress of the ceramic with different depth was shown in Figure 14. From Figure 14 we could see the maximal stress increased with the buried depth decreasing. The maximal stress was about $68.44 \mathrm{MPa}$ at the depth of $10 \mathrm{~mm}$. The allowable stress of the ceramic was $60-100 \mathrm{MPa}$ [13]. The maximal stress of the ceramic was not allowed to exceed the allowable stress. When the buried depth was under $30 \mathrm{~mm}$, the maximal stress changed quickly. However the buried depth exceeded $30 \mathrm{~mm}$, the maximal stress changed slowly. So the proper buried depth of the harvester should be selected as $30-50 \mathrm{~mm}$.

The open circuit of voltage of the harvester was about $64.422 \mathrm{~V}$ at the buried depth $40 \mathrm{~mm}$ and the single vehicle load 0.7 MPa. According to the Equation (7) the electric energy of the harvester was about $0.047 \mathrm{~mJ}$. The vibration frequency of the asphalt pavement was about $15 \mathrm{~Hz}$ [11]. So at the frequency $15 \mathrm{~Hz}$ the power of the harvester was about $0.705 \mathrm{~mW}$. 


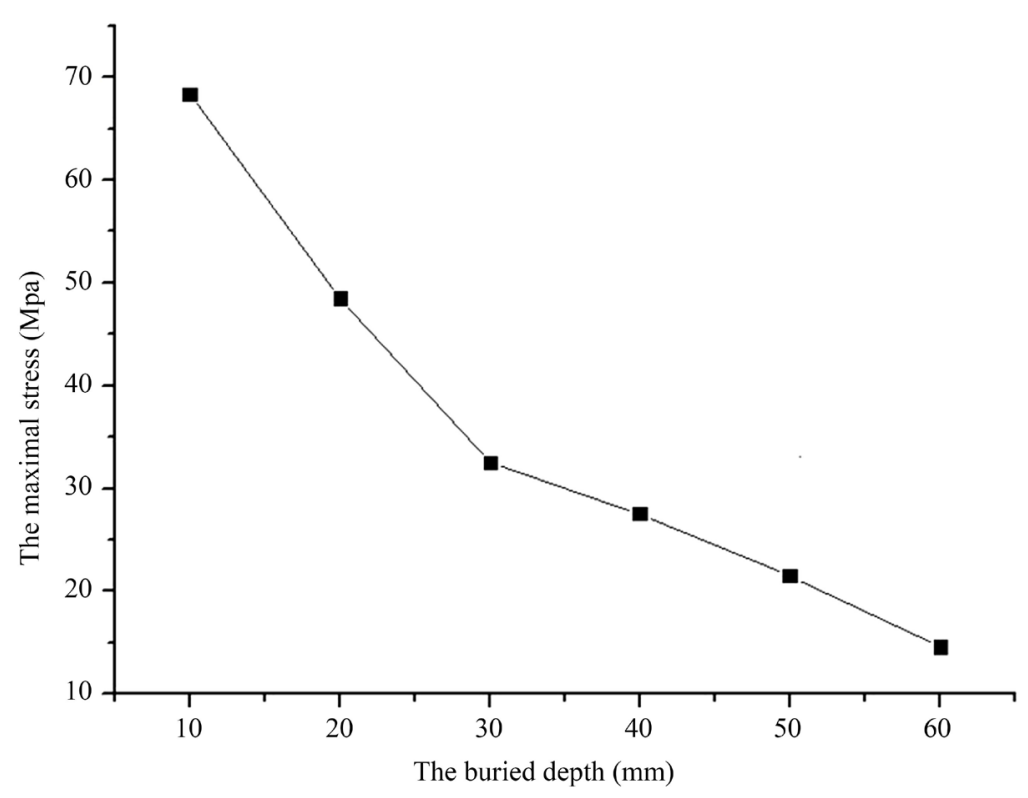

Figure 14. The maximal stress with different buried depth.

\subsection{The Effects of the Structure Parameters of the Harvester}

In the finite element model of the harvester shown in Figure 7, the effects of the structure parameters on the open circuit voltage were analyzed at the buried depth $40 \mathrm{~mm}$ and the single vehicle load $0.7 \mathrm{MPa}$. The effect of the ceramic length $L_{3}$ on the open circuit voltage was shown in Figure 15. From Figure 15 the open circuit voltage decreased with the ceramic length $L_{3}$ increasing.

The effect of the ceramic thickness $H_{3}$ on the open circuit voltage was shown in Figure 16. From Figure 16 the open circuit voltage increased with the ceramic length $H_{3}$ increasing.

The effect of the steel ring inner length $L_{2}$ on the open circuit voltage was shown in Figure 17. From Figure 17 the open circuit voltage increased with the steel ring inner length $L_{2}$ increasing.

The effect of the steel ring thickness $H_{1}$ on the open circuit voltage was shown in Figure 18. From Figure 18 the open circuit voltage increased with the steel ring thickness $H_{1}$ increasing.

The effect of the steel sheet thickness $H_{2}$ on the open circuit voltage was shown in Figure 19. From Figure 19 the open circuit voltage decreased with the steel sheet thickness $\mathrm{H}_{2}$ increasing.

According to Figures 15-19, the sensitivity of the open circuit voltage on the each structure parameter was shown in Figure 20. The structure parameters $L_{2}, H_{1}, H_{2}, L_{3}, H_{3}$ were described as 1,2,3,4,5. From Figure 20 we could see that the maximal sensitivity was the ceramic thickness $H_{3}$. The second was the steel ring thickness $H_{1}$ and the steel sheet thickness $H_{2}$. The minimum was the ceramic length $L_{3}$ and the steel ring inner length $L_{2}$. So the structure parameters $H_{3}, H_{1}, H_{2}$ should be adjusted to advanced the open circuit voltage of the harvester.

According the finite method analysis the deformation difference percent $p$ did mot change with the different structure parameters.

\section{Conclusions}

1) A square canister piezoelectric energy harvester was proposed to harvest vibration energy in asphalt pavement. The harvester worked by the piezoelectric constant $d_{33}$.

2) The finite element model of the single harvester was constructed. By the finite element analysis the open circuit voltage increased with the outer load increasing and the open circuit voltage on the surface of the two ceramics of the harvester was about $2.076 \mathrm{~V}$ at the outer load $2000 \mathrm{~Pa}$.

3) The finite element model of the harvester buried in the asphalt pavement was constructed. The open circuit voltage of the harvester decreased with the buried depth increasing. When the harvester was closer to the surface of the asphalt pavement the influence on the asphalt pavement was more greatly. The proper buried depth of the 


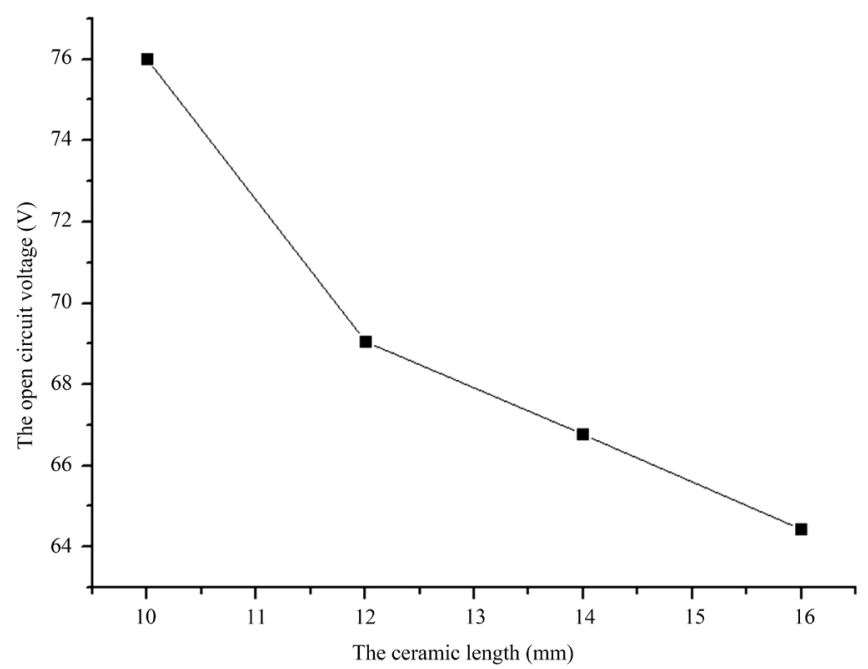

Figure 15. The effect of the ceramic length $L_{3}$ on the open circuit voltage.

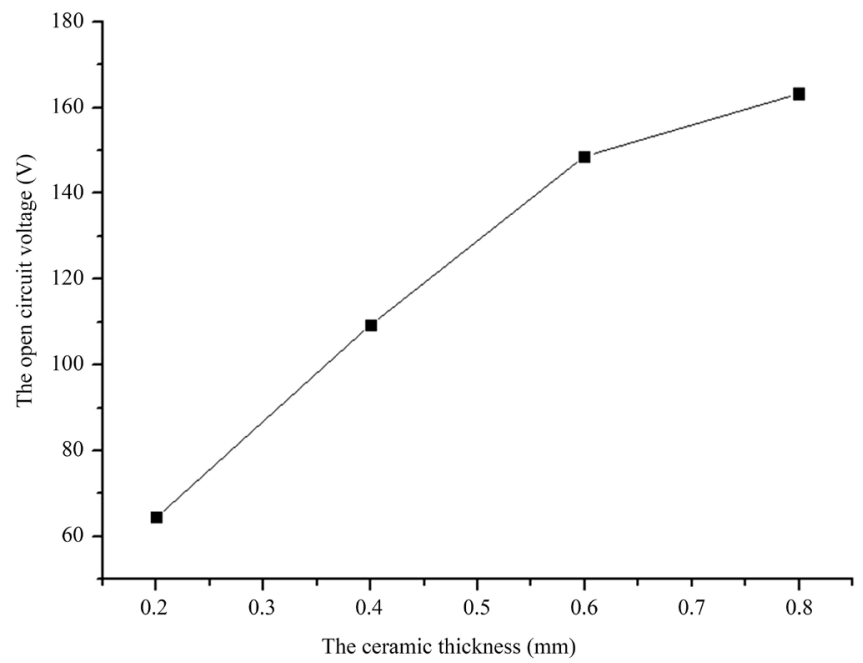

Figure 16. The effect of the ceramic thickness $H_{3}$ on the open circuit voltage.

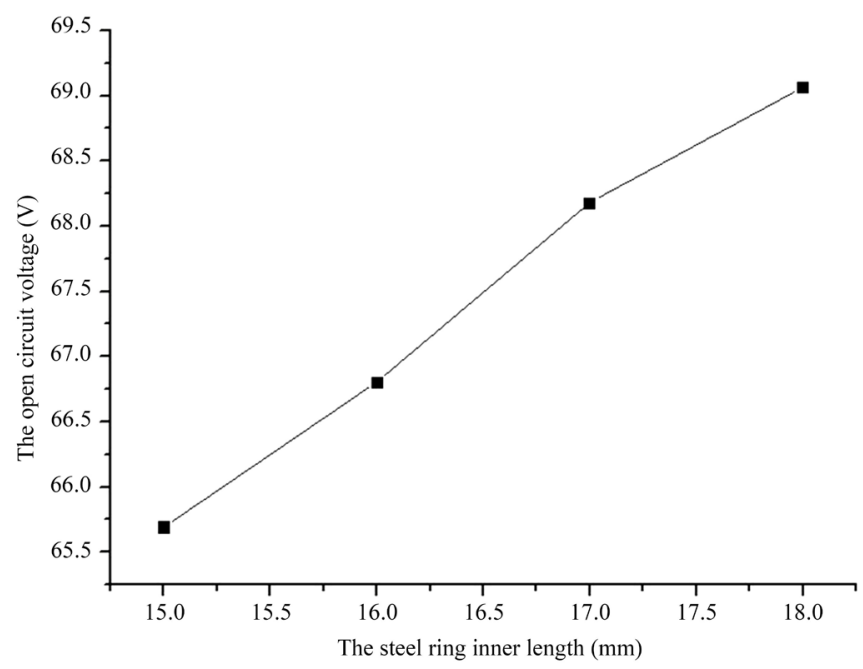

Figure 17. The effect of the steel ring inner length $L_{2}$ on the open circuit voltage. 


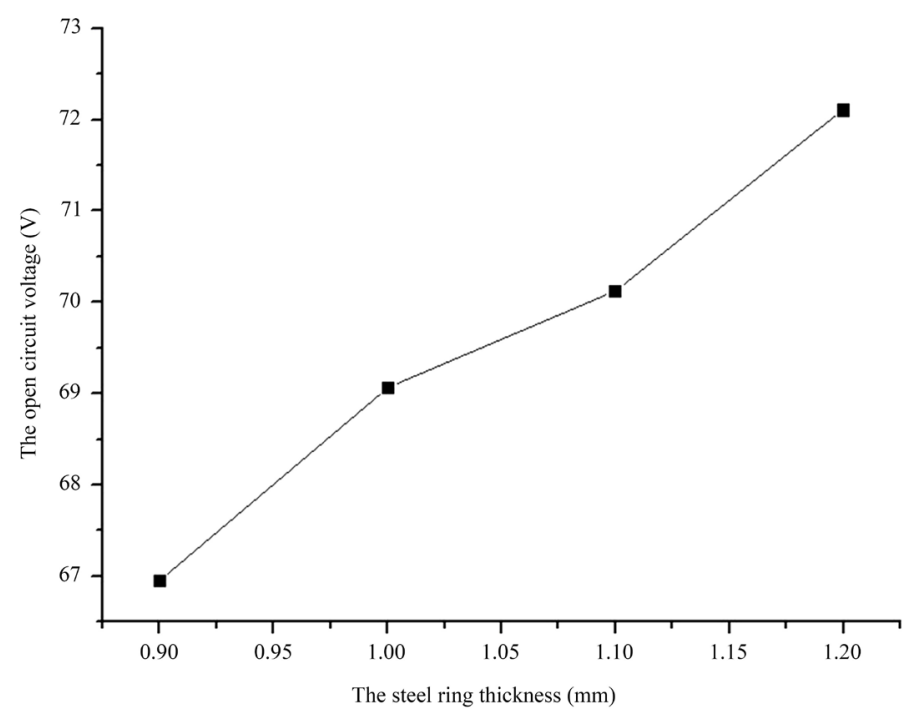

Figure 18. The effect of the steel ring thickness $H_{1}$ on the open circuit voltage.

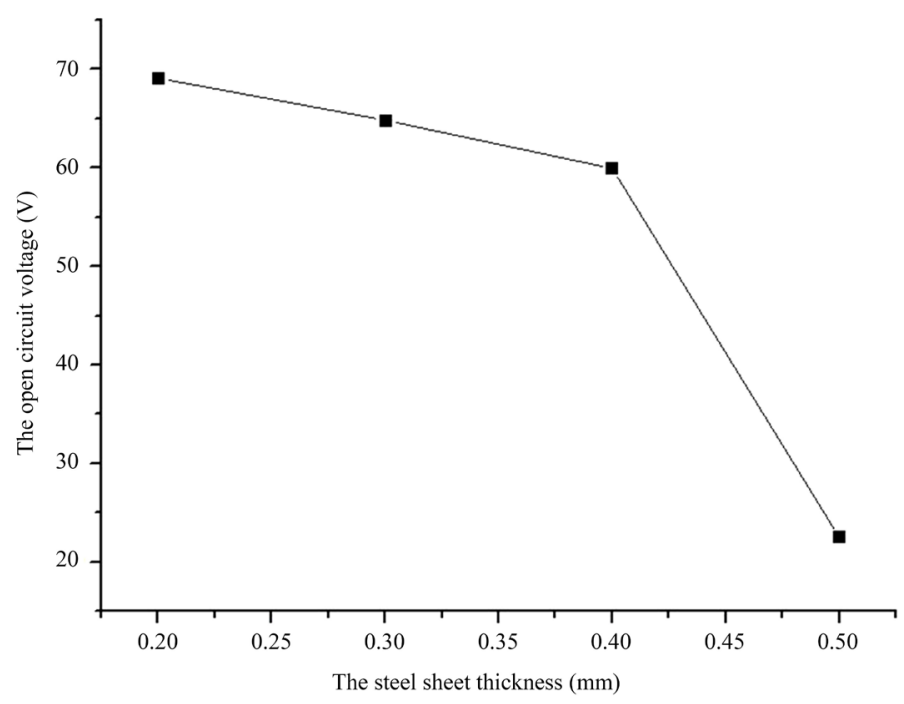

Figure 19. The effect of the steel ring thickness $H_{2}$ on the open circuit voltage.

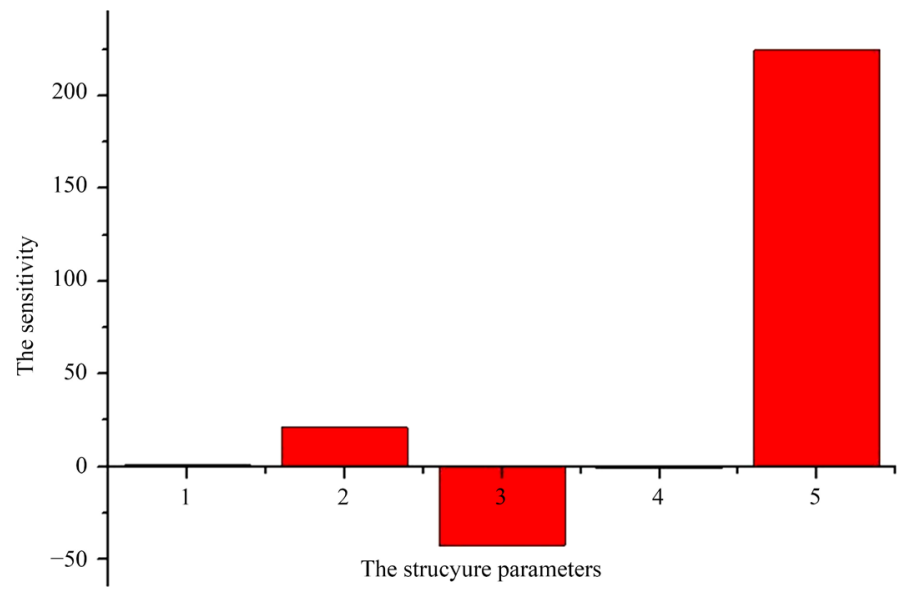

Figure 20. The sensitivity of the open circuit voltage on the each structure parameter. 
harvester should be selected as 30 - $50 \mathrm{~mm}$ because the maximal stress of the ceramic was not allowed to exceed the allowable stress.

4) The effects of the structure parameters of the harvester on the open circuit voltage were analyzed at the buried depth $40 \mathrm{~mm}$ and the single vehicle load $0.7 \mathrm{MPa}$. The sensitivity of the open circuit voltage on the each structure parameter was analyzed. The sensitivity of the structure parameters $H_{3}, H_{1}, H_{2}$ was higher than the other parameters. So these parameters should be adjusted to advance the open circuit voltage of the harvester.

5) At the buried depth $40 \mathrm{~mm}$, the single vehicle load $0.7 \mathrm{MPa}$ and the vibration frequency of the asphalt pavement $15 \mathrm{~Hz}$, the electric energy of the harvester was about $0.047 \mathrm{~mJ}$ and the power of the harvester was about $0.705 \mathrm{~mW}$.

\section{Acknowledgements}

This work was financially supported the National Natural Science Foundation of China (No. 51175359), The $4^{\text {th }}$ “333 Engineering” Research Funding Project of Jiangsu Procince (No. BRA2014086), Sunzhou vocational university research project (No. 2014SZDCC01).

\section{References}

[1] Lee, J. and Bumkyoo, C. (2012) A Study on the Piezoelectric Energy Conversion System using Motor Vibration. International Journal of Precision Engineering and Manufacturing, 13, 573-579. http://dx.doi.org/10.1007/s12541-012-0073-8

[2] Glynne Jones, P., Tudorm, J., Beeby, S.P., et al. (2004) An Electromagnetic Vibration-Powered Generator for Intelligent Sensor Systems. Sensors and Actuators A, 110, 344-349. http://dx.doi.org/10.1016/j.sna.2003.09.045

[3] Mitcheson, P.D., Miao, P., Stark, B.H., et al. (2004) MEMS Electrostatic Micropower Generator for Low Frequency Operation. Sensors and Actuators A, 115, 523-529. http://dx.doi.org/10.1016/j.sna.2004.04.026

[4] Choi, W.J., Jeon, Y., Jeong, J.H., et al. (2006) Energy Harvesting MEMS Device Based on Thin Film Piezoelectric Cantilevers. Journal of Electroceramics, 17, 543-548. http://dx.doi.org/10.1007/s10832-006-6287-3

[5] Priya, S. (2007) Advances in Energy Harvesting Using Low Profile Piezoelectric Transducers. Journal of Electroceramics, 19, 165-182.

[6] http://www.moc.gov.cn/zfxxgk/bnssj/zhghs/201405/t20140513_1618277.html

[7] http://www.innowattech.co.il/index.aspx

[8] Lee, J., Lee, M. and Oh, J. (2010) Study on the Energy Conversion from the Dynamic Load of Vehicles on the Road Using Piezoelectric Material. Materials Science Forum, 658, 57-60. http://dx.doi.org/10.4028/www.scientific.net/MSF.658.57

[9] Kymissis, J., Kendall, C. and Paradiso (1998) Parasitic Power Harvesting in Shoes. IEEE Proceedings of the Second IEEE International Conference on Wearable Computing, Washington DC, 132-139.

[10] Orr, R.J. and Abowd, G.D. (2000) The Smart Floor: A Mechanism for Nature User Identification and Tracking. ACM Conference on Human Factors in Computing, New York, 275-276.

[11] Zhao, H.D., Yu, J. and Ling, J.M. (2000) Finite Element Analysis of Cymbal Piezoelectric Transducers for Harvesting Energy from Asphalt Pavement. Journal of the Ceramic Society of Japan, 118, 909-915.

[12] Wang, S. and Lam, K.H. (2007) Energy Harvesting with Piezoelectric Drum Transducer. Applied Physics Letters, 90, 506-509.

[13] Kuna, M. (2010) Fracture Mechanics of Piezoelectric Materials-where Are We Right Now. Engineering Fracture Mechanics, 77, 309-326. http://dx.doi.org/10.1016/j.engfracmech.2009.03.016 